\title{
SCREENING OF SOME SELECTED COMPOUNDS IN ROSELLA (Hibiscus sabdariffa L.) TARGETING OF COMPLEX HUMAN PROGRAMMED DEATH-1 AND ITS LIGAND-1 (hPD- 1/PD-L1) AS IMUNOMODULATORY ACTIVITY: In silico APPROACH
}

\author{
Wa Ode Yuliastri ${ }^{1,2,}{ }^{凶}$, Ajeng Diantini ${ }^{1}$, Mohammad Ghozali $^{3}$, I. sahidin ${ }^{4}$ \\ and Dwi Syah Fitra Ramadhan ${ }^{2}$ \\ ${ }^{1}$ Faculty of Pharmacy, Universitas Padjadjaran, Bandung-45363, West Java, Indonesia \\ ${ }^{2}$ Department of Pharmacy, STIKES Mandala Waluya Kendari, Kendari-93231, \\ Southeast Sulawesi, Indonesia \\ ${ }^{3}$ Department of Biochemistry and Molecular Biology, Universitas Padjadjaran Medical School, \\ Bandung-45363, West Java, Indonesia \\ ${ }^{4}$ Faculty of Pharmacy, Universitas Halu Oleo, Kendari-93231, Southeast Sulawesi, Indonesia \\ Corresponding Author: waodeyuliastri@yahoo.com
}

\begin{abstract}
Human programmed death-1 with its ligand (hPD-1/PD-L1) is a promising target to blockade the checkpoints immunology as anticancer therapy. Small molecules inhibitor of checkpoints immunology currently develop. Natural bioactive compounds in rosella have the potential as promising small molecules that can inhibit the complex of hPD-1/PD-L1. So this research aimed to determine the bioactive compounds in rosella against hPD-1/PD-L1 by in silico molecular docking and molecular dynamics studies. A total 16 compounds in rosella were selected and downloaded through the Pubchem and KNapSAcK compound databases. The compounds were then docked into the binding pocket of hPD-1/PD-L1 protein and then simulated by the molecular dynamics method. It was obtained three best compounds that have the best binding energy and interaction i.e. delphinidin-3-sambubioside, hibiscetin3-glucoside, and quercetin-3-rutinoside. The molecular dynamics simulation during $100 \mathrm{ns,} \mathrm{showed} \mathrm{the} \mathrm{three}$ compounds have good stability, that analyzed by the RMSD, RMSF, and MM-PBSA binding free energy calculation. The delphinidin-3-sambubioside showed the lowest binding free energy, i.e. $-33.161 \mathrm{KJ} / \mathrm{mol}$, and provided the best stability compared to the other compounds.
\end{abstract}

Keywords: Rosella, Hibiscus sabdariffa L., In silico, hPD-1/PD-L1, Immunomodulator

RASĀYAN J. Chem., Vol. 14, No.2, 2021

\section{INTRODUCTION}

Cancer is a disease class that is considered the most dangerous for society, based on Globocan data in 2018. ${ }^{1}$ The new cancer incidence rate is estimated at 18.1 million, with the death rate reaching 9.6 million. Along with the increase in research for cancer, it has been able to develop knowledge of cancer therapy with the latest approach, i.e. cancer immunotherapy. ${ }^{2,3}$ Immunotherapy can fight cancer growth by binding to T-cells, so that the tumor and cancer cells are lysed and eradicated. ${ }^{4}$ One of the immunotherapy that is considered effective in increasing the immune system in inhibiting the growth of cancer cells is by blockade the checkpoints immunology ${ }^{5}$, i.e. programmed death-1 (PD-1). ${ }^{6,7}$ Programmed death-1 (PD-1) associated with apoptosis which is expressed on the surface of T-cells. ${ }^{8}$ PD1 ligand (PD-L1) is expressed as a suppressor of the normal immune system, by forming a complex with PD-1, to regulate the balance between T-cell activation, tolerance, and immunopathology. ${ }^{9}$ However, PDL1 is also expressed in cancer cells to take advantage of the immunosuppression function to avoid being killed by $\mathrm{T}$ cells $\mathrm{s}^{10}$, which are reported to occur in various types of cancer such as small-cell lung cancer, melanoma, leukemia, etc. ${ }^{11-13}$ The development of immune checkpoint pathways targeting PD-1/PD-L1 focuses mostly on monoclonal antibodies, in contrast to the development of small-molecule-inhibitors, 
RASĀYAN J. Chem.

Vol. 14 | No. 2 |1394-1401| April - June | 2021

which are still far behind. However, small-molecule-inhibitors can be low-cost and can be given in various administrations. Some researchers have tried to develop small-molecule-inhibitor to immune checkpoint inhibitor PD1/PD-L1 from peptides. ${ }^{14}$ However, until now, only a few have developed or identified the potential of natural metabolite compounds as immune checkpoint inhibitors. Rosella (Hibiscus sabdariffa L.) reported to contain various bioactive compounds with various pharmacological activities, among the compounds class that play a role in the activity, i.e. flavonoids, phenolic, and anthocyanin..$^{15}$ One of the specific pharmacological activities of the compounds in roselle has been reported to have immune checkpoint inhibitor activity ${ }^{16}$. However, until now there have been no reports of specific activity of roselle against the PD-1/PD-L1 target. Therefore, we tried to screened and identify the compounds that contained in roselle which have been studied as immunomodulators, as small molecule inhibitors targeting immune checkpoint inhibitor PD-1/PD-L1 by in silico approach.

\section{EXPERIMENTAL}

\section{Bioactive Compounds Preparation}

The bioactive compounds in rosella were selected based on the KNapSAcK database (http://www.knapsackfamily.com/KNApSAcK $/{ }^{17}$ and http://knapsack3d.sakura.ne.jp/) ${ }^{18}$ with the keyword Latin species name "Hibiscus sabdariffa L.", The bioactive compounds that selected were eugenol, delphinidin 3-sambubioside, gossypetin, hibiscetin, hibiscetin 3-glucoside, myricetin, protocathecuic acid, quercetin. Apart from the KNapSAcK database, we selected compounds based on those that have been reported to have immunomodulatory activity, i.e. 5-hydroxymethyl furfural, chlorogenic acid, cyanidin 3-sambubioside, gallic acid, methyl gallate, quercetin 3-glucoside, quercetin 3-rutinoside, were obtained from the PubChem compound database (https://pubchem.ncbi.nlm.nih.gov/). ${ }^{19}$

\section{Protein Preparation}

The complex structure of human programmed death-1 (PD-1) and its ligand PD-L1 (hPD-1/PD-L1) obtained from Protein Data Bank (http://www.rcsb.org/pdb/), with PDB ID: 4ZQK ${ }^{20}$ with crystallography resolution $2.45 \AA$. Furthermore, The downloaded protein prepared by removing the unique ligand and water molecules and then added the polar hydrogen and charged with Kollman charges ${ }^{21,22}$. The protein preparation procedure was conducted using BIOVIA Discovery Studio 2017 and Autodock tools 1.4.6. ${ }^{23}$

\section{Molecular Docking Simulation}

The determination of the active site was carried out on the 4ZQK protein using BIOVIA Discovery Studio 2017. The active site identification was carried out using the amino acid in binding pocket catalytic, that was the pocket of small molecule inhibitor of PD-1 / PD-L1 based on previous research by the desk in 2018. The amino acid in the binding pocket catalytic that was focused in the search was i.e. Glu:136, Tyr:68, Arg:113, Tyr: $123^{24}$. the attributes of the binding pocket. Furthermore, we docked all of the bioactive compounds in rosella that have been obtained into the binding pocket of PD-1 / PD-L1 complex using autodock 4 .

\section{Molecular Dynamics of Bioactive Compounds in Rosella}

The compounds in roselle were ranked based on molecular docking binding energy, then the top threeranked compounds were continued to the molecular dynamics (MD) simulation stage. The MD simulation was carried out with the AMBER99SB-ILDN force field. ${ }^{23-25}$ Ligand topology was made using $\mathrm{ACPYPE}^{26}$. The electrostatic force, neutralization of the system, and solvation were carried out using the Particle Mesh Ewald method ${ }^{27}$, carried out by adding $\mathrm{Na}^{+}$and $\mathrm{Cl}^{-}$ions, and with the TIP3P water cube model $^{28}$, respectively. Furthermore, $100 \mathrm{~ns}$ of MD production was performed with a 2 fs timestep. The simulations were carried out using Gromacs 2016.3 software. ${ }^{29}$ Afterward, the Root Mean Square Deviation (RMSD), Root Mean Square Fluctuation (RMSF), and binding free energy (MM-PBSA) were used to measure the stability of complex systems. MM-PBSA calculations were performed using the g_mmpbsa package which is integrated with the Gromacs software. According to MM-PBSA method, the binding free energy of complex $\left(\Delta \mathrm{G}_{\text {bind }}\right)$ is the difference between the free energies of the complex $\left(\Delta \mathrm{G}_{\text {complex }}\right)$ and the unbound receptor $\left(\Delta \mathrm{G}_{\mathrm{rec}}\right)$ and the free ligand $\left(\Delta \mathrm{G}_{\mathrm{lig}}\right)^{30}$. 
RASĀYAN J. Chem.

Vol. 14 | No. 2 |1394-1401| April - June | 2021

The binding free energy of each ligand-protein complexes were carried out based on the output of MD simulation on 1000 snapshots taken from all $100 \mathrm{~ns}$ simulation trajectories ${ }^{31}$.

\section{RESULTS AND DISCUSSION}

\section{Molecular Docking Simulation}

The active site was determined based on the receptor cavities, it is obtained the active site of the complex was $\mathrm{X}=-1.113, \mathrm{Y}=46.195$, dan $\mathrm{Z}=99.22$. The active site has amino acid residues that are identical to the active site previously reported by the desk, 2018 from our analysis. Each bioactive compound was then docked into the active site. The binding energy of each ligand can be seen in Table-1. Top 3 ranked bioactive compounds with the best binding energy were quercetin 3-rutinoside $(-7.6 \mathrm{kcal} / \mathrm{mol})$, delphinidin 3-sambubioside $(-7.1 \mathrm{kcal} / \mathrm{mol})$, and hibiscetin 3 -glucoside $(-7.1 \mathrm{kcal} / \mathrm{mol})$. The binding catalitic on the active site of inhibitory ligand that reported before has some important amino acids i.e. Glu:136, Tyr:68, Arg:113, Tyr:123. The binding mode of quercetin 3-routineoside and hibiscetin 3glucoside showed hydrogen bond interaction with one of the catalytic amino acids, i.e. Glu:136, while delphinidin 3-sambubioside interacts with 2 catalytic amino acids, namely Glu: 136 and Arg: 113.

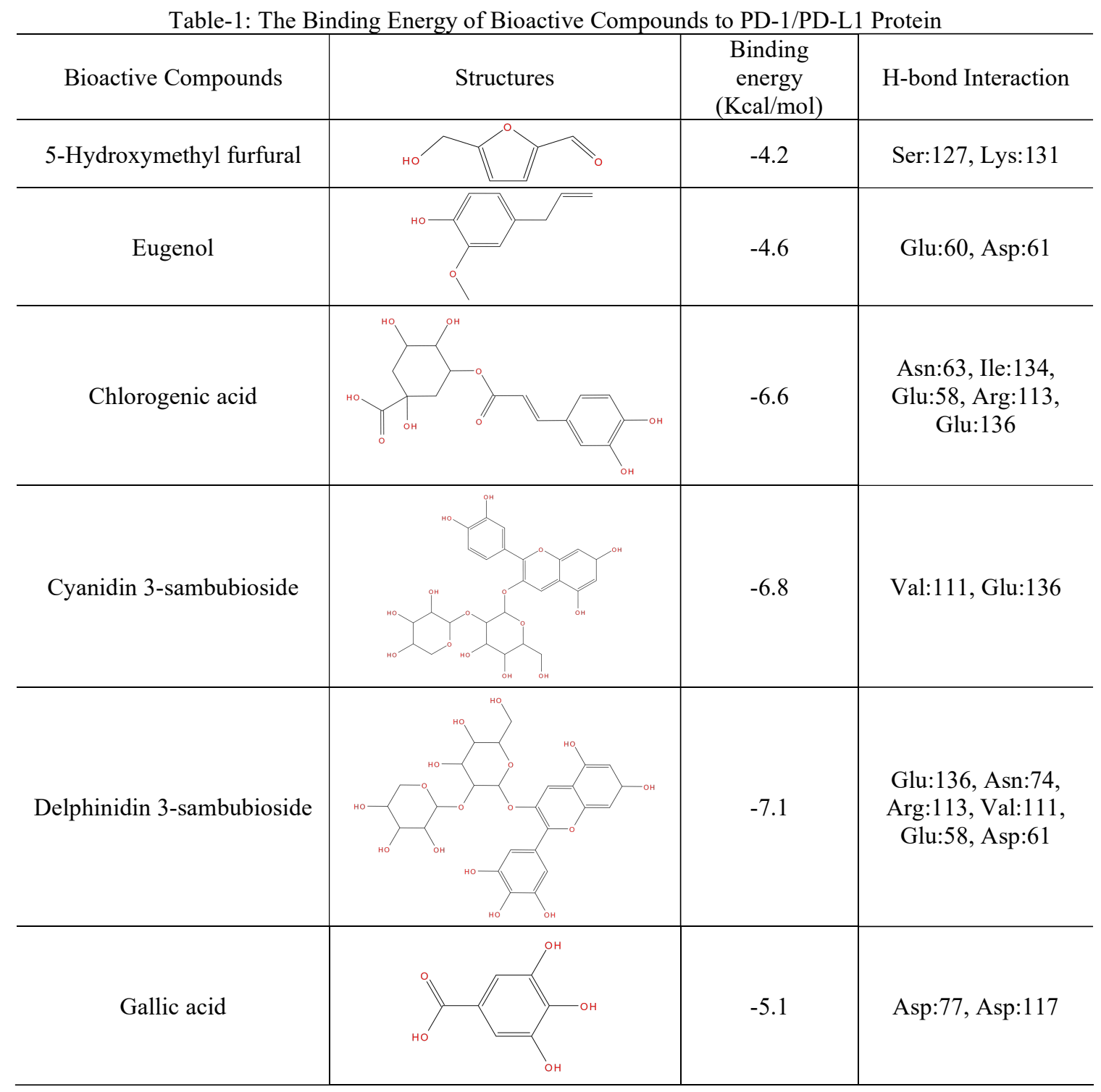


RASĀYAN J. Chem.

Vol. 14 | No. 2 |1394-1401| April - June | 2021

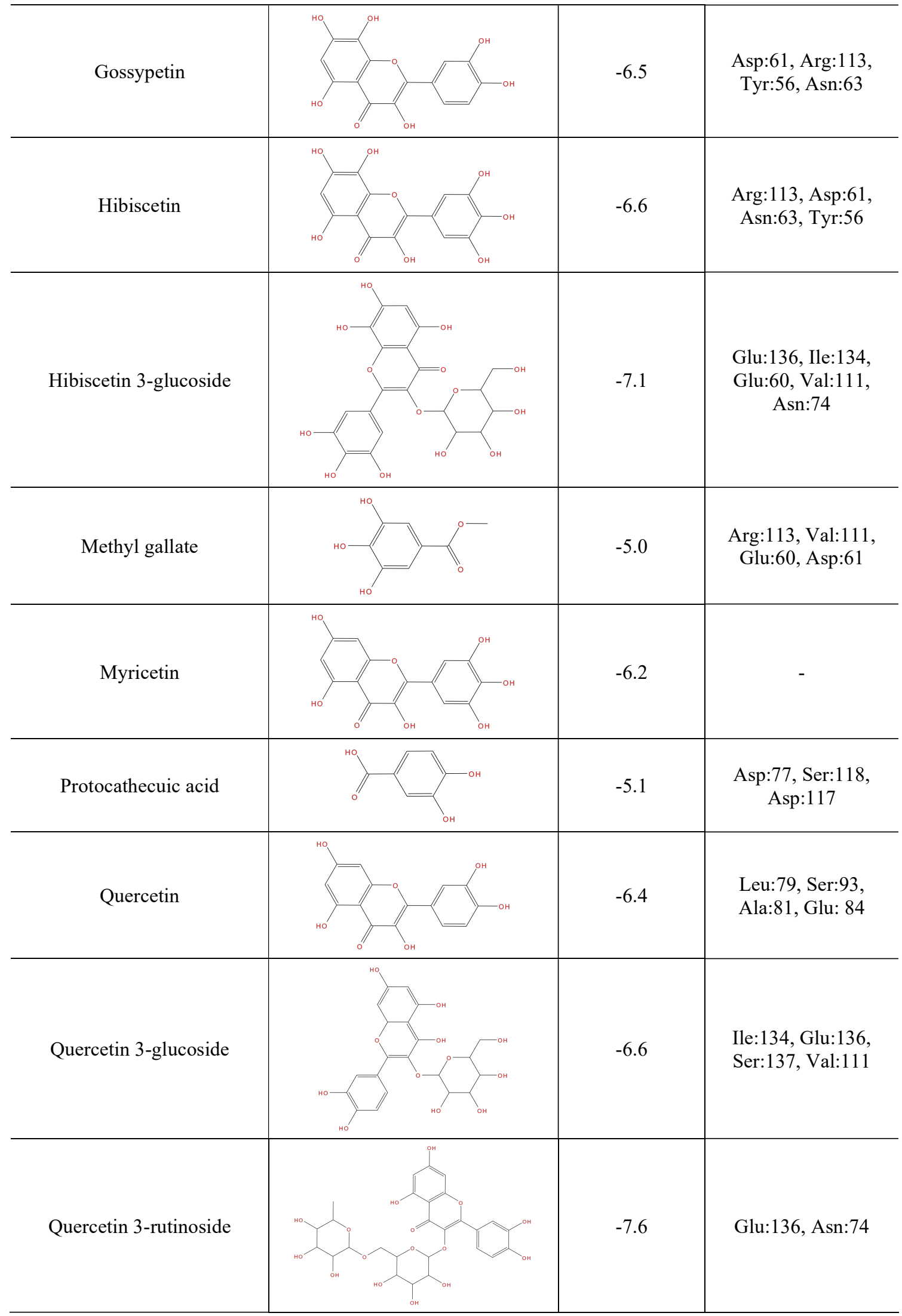


RASĀYAN J. Chem.

Vol. 14 | No. 2 |1394-1401| April - June | 2021

The molecular interaction of the best-three bioactive compounds in the hPD-1/PD-L1 protein was revealed (Figs.-1 to 3). The delphinidin-3-sambubioside compound interactions were conventional hydrogen bonds (Glu:136, Asn:74, Arg:113, Val:111, Glu58, Asp:61), pi-cation (Arg:113), pi-anion (Glu:58), pi-alkyl (Val:111), and some van der Waals interaction with 9 amino acids. Hibiscetin-3glucoside interactions were conventional hydrogen bond (Glu:136, Asn:74, Val:111, Glu:60, Ile:134), pication (Arg:113), pi-anion (Glu:136), pi-alkyl (Val:111), carbon-hydrogen bond (Arg:113), Unfavorable donor-donor (Glu:60 and Asn:74) and some van der Waals interaction with 11 amino acids. Quercetin-3rutinoside interactions were conventional hydrogen bond (Glu:136, Asn:74), pi-cation (Arg:113), pi-anion (Glu:58), pi-alkyl (Val:111), and van der Waals interaction with 13 amino acids. The molecular interaction analysis showed that the three compounds have high similarity in amino acid interactions, but different in the type of interactions, as can be observed at 2D interaction analysis. Hibiscetin-3-glucoside showed higher intensity in a total interaction at the binding pocket of hPD-1/PD-L1.
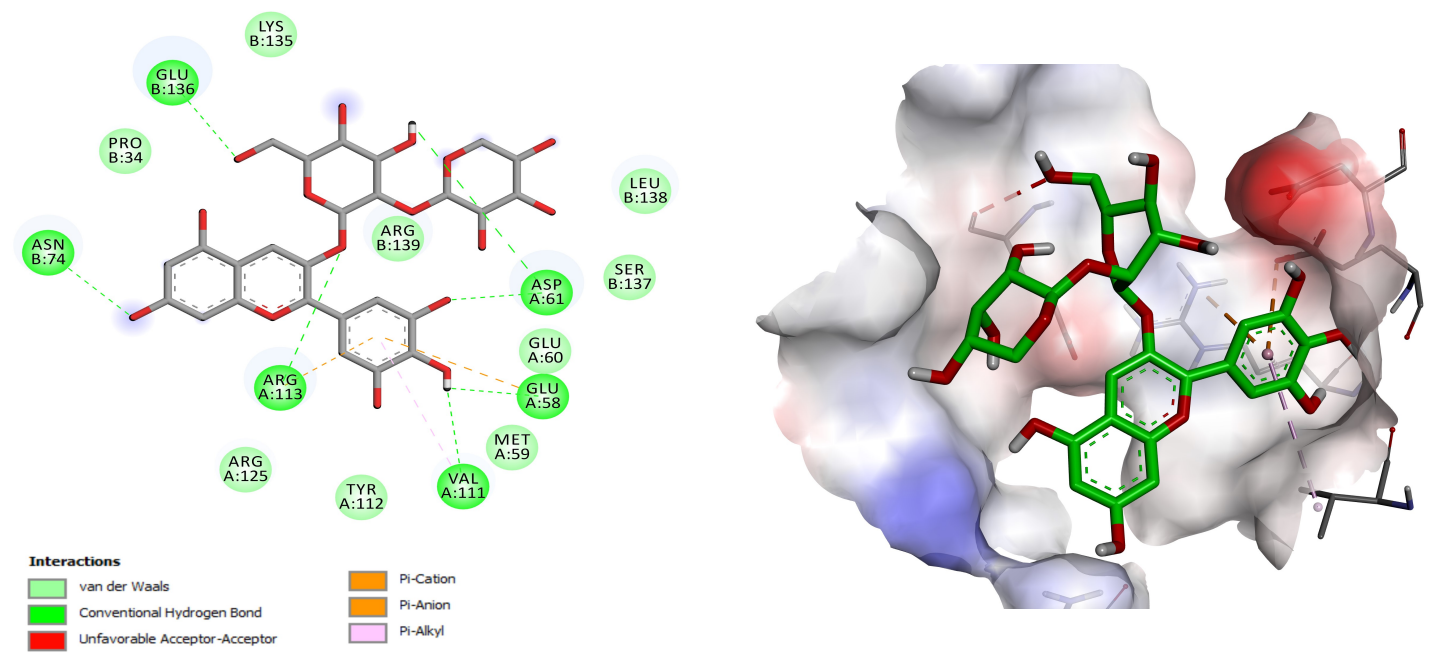

Fig.-1: Delphinidin-3-sambubioside interaction in hPD-1/PD-L1

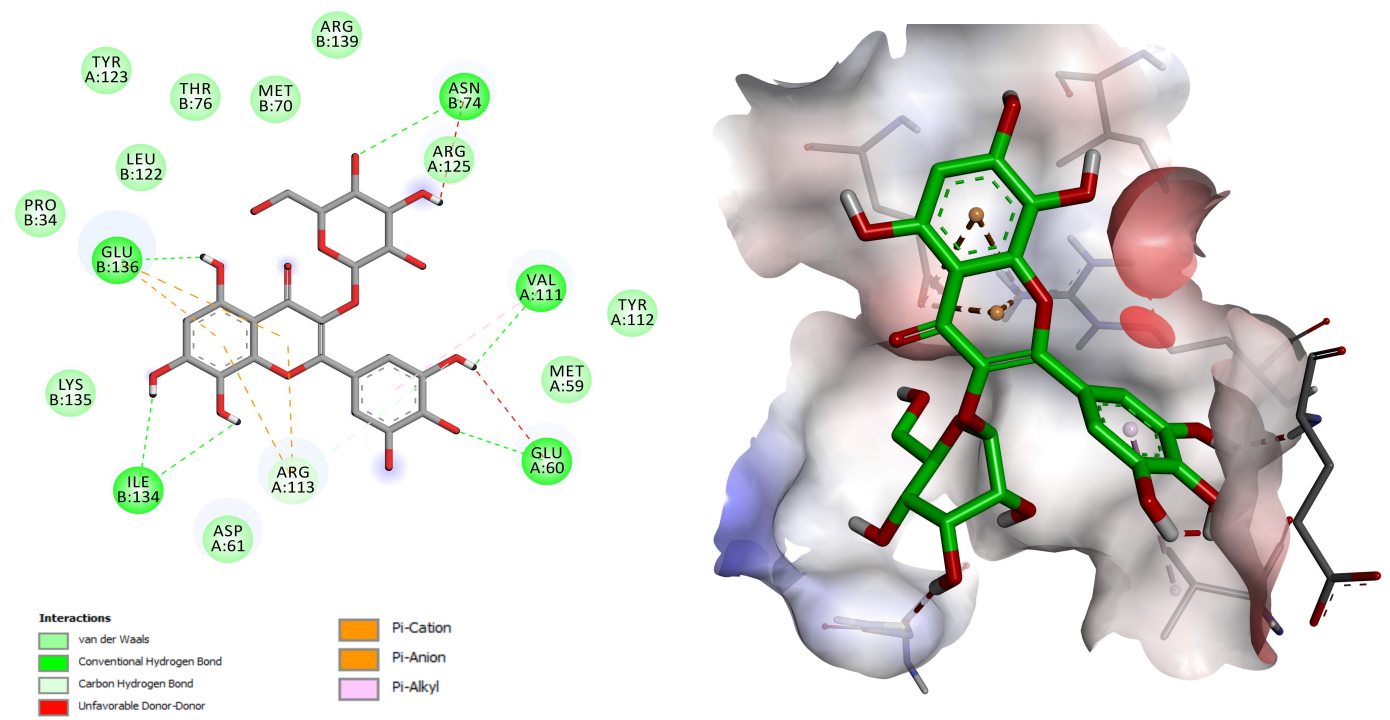

Fig.-2: Hibiscetin-3-glucoside interaction in hPD-1/PD-L1 
RASĀYAN J. Chem.

Vol. 14 | No. 2 |1394-1401| April - June | 2021

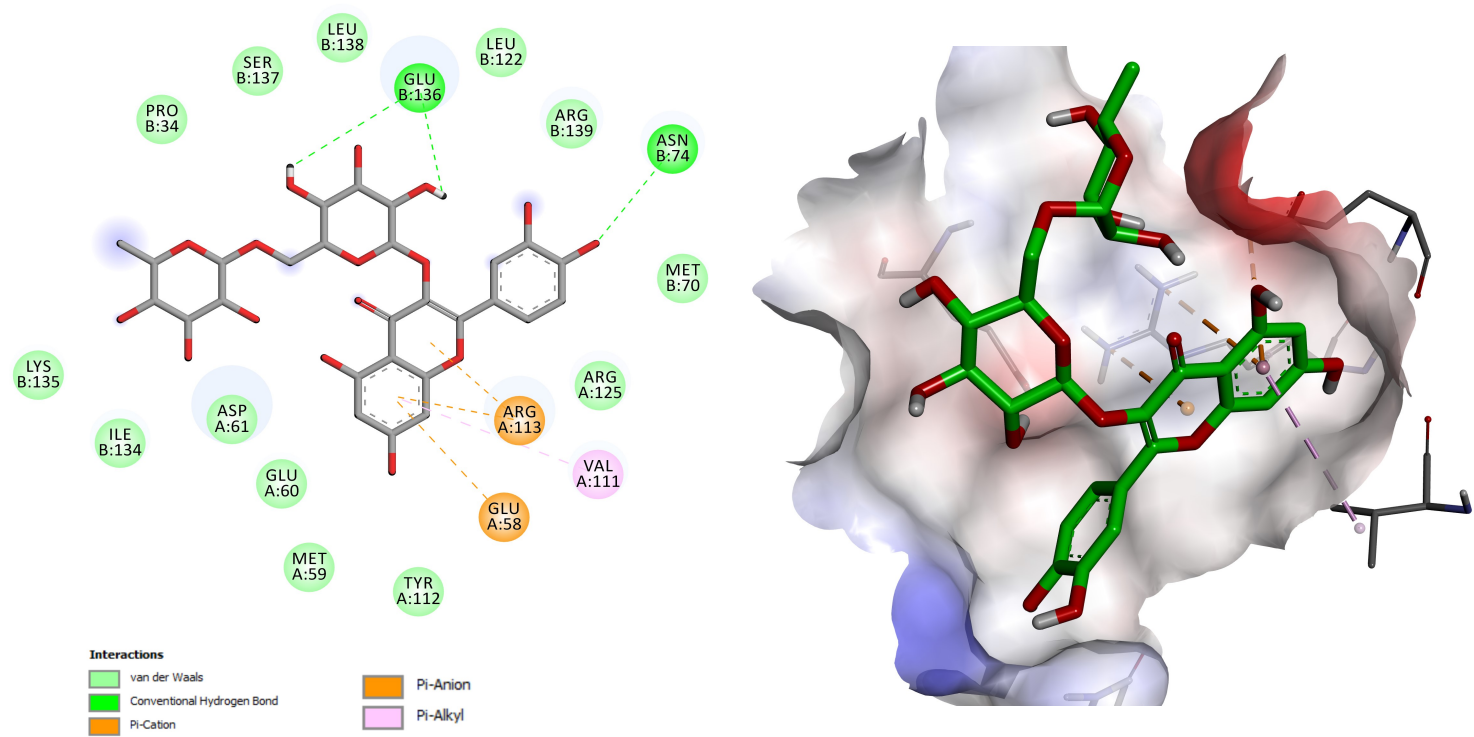

Fig.-3: Quercetin-3-rutinoside interaction in hPD-1/PD-L1

\section{Molecular Dynamics Simulation and Stability Analysis}

The top-three ranked bioactive compounds from roselle then identified their stability at the hPD-1/PD-L1 protein complex, to see their bond strength as an inhibitor that can disrupt the binding of the hPD-1/PDL1 complex. Molecular dynamics was successfully carried out during 100 ns simulations of delphinidin3-sambubioside - hPD-1/PD-L1 complex, hibiscetin-3-glucoside - hPD-1/PD-L1 complex, and quercetin3-rutinoside - hPD-1/PD-L1 complex. The binding stability, RMSD and RMSF, of each complex were analyzed that can be seen in Fig.-4. The average of RMSD fluctuations were $2.37 \AA$ (delphinidin-3sambubioside - hPD-1/PD-L1 complex), $2.04 \AA$ (hibiscetin-3-glucoside - hPD-1/PD-L1 complex), and $2.36 \AA$ (quercetin-3-rutinoside - hPD-1/PD-L1 complex). The average of RMSD fluctuations were $1.29 \AA$ (delphinidin-3-sambubioside - hPD-1/PD-L1 complex), $1.09 \AA$ (hibiscetin-3-glucoside - hPD-1/PD-L1 complex), and $1.20 \AA$ (quercetin-3-rutinoside - hPD-1/PD-L1 complex). The RMSD graph showed delphinidin-3-sambubioside and quercetin-3-rutinoside fluctuation characteristic during the simulation was similar, and hibiscetin-3-glucoside showed lower fluctuation during 100 ns simulation. The RMSF graph showed higher residue fluctuation in amino acid numbers 141-146 in delphinidin-3-sambubioside complex. However, the fluctuation of amino acids between the three ligand complexes shows a fairly high similarity
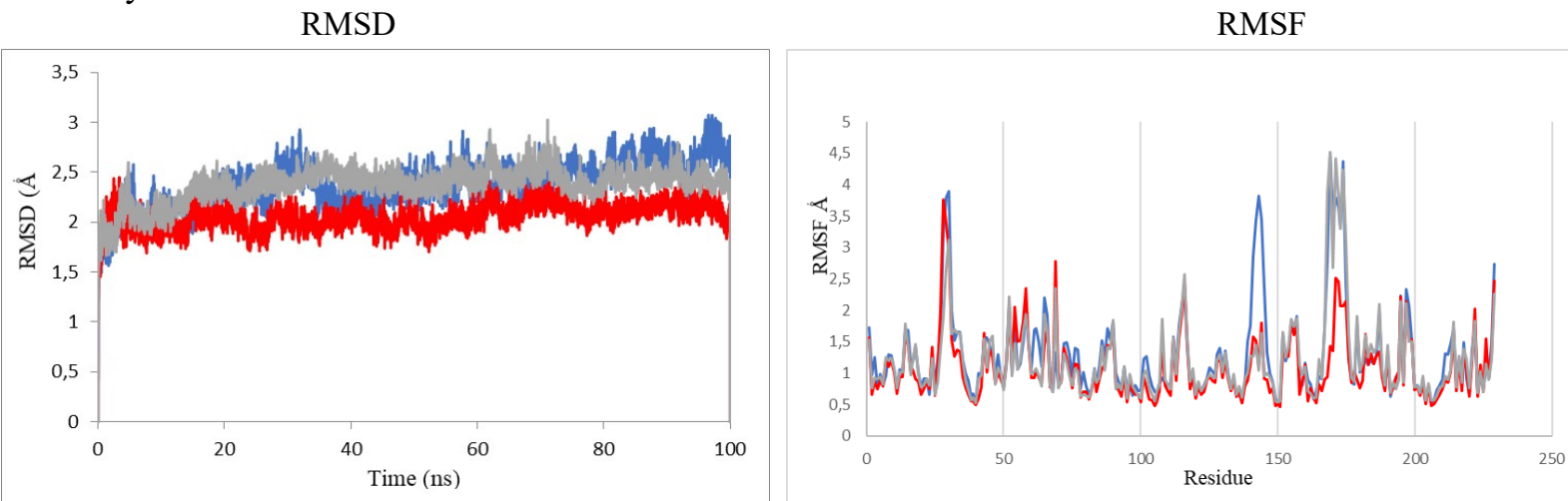

Fig.-4: Comparison of the RMSD and RMSF Graph of delphinidin-3-sambubioside (blue), hibiscetin-3-glucoside (red), and quercetin-3-rutinoside (grey) in complex with hPD-1/PD-L1

\section{Binding Free Energy Calculation}

The binding free energy was done calculated using MM-PBSA method from timestep 0-100 ns (Table-2). Van der Waals, electrostatic and SASA energies in both complex systems showed a negative value, while 
RASĀYAN J. Chem.

Vol. 14 | No. 2 |1394-1401| April - June | 2021

the polar solvation energy showed a positive value. These results indicated, in all system complex, the polar solvation energy terms opposed the binding, van der Waals, electrostatic and SASA energies favored the binding. The best binding free energy was represented by the delphinidin-3-sambubioside compound with total binding energy $-33.161 \mathrm{KJ} / \mathrm{mol}$, while the hibiscetin-3-glucoside and quercetin-3rutinoside represented total binding energy $-12.721 \mathrm{KJ} / \mathrm{mol}$ and $-14.317 \mathrm{KJ} / \mathrm{mol}$, respectively. The lower binding free energy of the delphinidin-3-sambubioside compound than other, majority was due to the contribution by the low polar solvation energy $(277.597 \mathrm{KJ} / \mathrm{mol}$ in delphinidin-3-sambubioside : 296.088 and $299.962 \mathrm{KJ} / \mathrm{mol}$ in other compounds) and SASA energy $(-16.836 \mathrm{KJ} / \mathrm{mol}$ in delphinidin-3sambubioside : -15.674 and $-16.057 \mathrm{KJ} / \mathrm{mol}$ in other compounds).

Table-2: The MM-PBSA Binding Free Energy Calculation of delphinidin-3-sambubioside, hibiscetin-3-glucoside, and quercetin-3-rutinoside in Complex with hPD-1/PD-L1 Protein

\begin{tabular}{c|c|c|c|c|c}
\hline $\begin{array}{c}\text { Ligand Complex } \\
\text { with hPD-1/PD- } \\
\text { L1 }\end{array}$ & $\begin{array}{c}\text { Van de waals } \\
\text { energy } \\
(\mathrm{KJ} / \mathrm{mol})\end{array}$ & $\begin{array}{c}\text { Electrostatic } \\
\text { Energy } \\
(\mathrm{KJ} / \mathrm{mol})\end{array}$ & $\begin{array}{c}\text { Polar Solvation } \\
\text { Energy } \\
(\mathrm{KJ} / \mathrm{mol})\end{array}$ & $\begin{array}{c}\text { SASA Energy } \\
(\mathrm{KJ} / \mathrm{mol})\end{array}$ & $\begin{array}{c}\text { Total Binding } \\
\text { Energy } \\
(\mathrm{KJ} / \mathrm{mol})\end{array}$ \\
\hline delphinidin-3- & $-138.380+/-$ & -155.542 & 277.597 & -16.836 & -33.161 \\
sambubioside & 21.783 & $+/-33.511$ & $+/-38.738$ & $+/-1.522$ & $+/-22.783$ \\
\hline hibiscetin-3- & -141.115 & -152.020 & 296.088 & -15.674 & -12.721 \\
glucoside & $+/-16.450$ & $+/-34.237$ & $+/-47.261$ & $+/-1.059$ & $+/-22.127$ \\
\hline quercetin-3- & -116.858 & -181.364 & 299.962 & -16.057 & -14.317 \\
rutinoside & $+/-19.517$ & $+/-45.697$ & $+/-50.429$ & $+/-1.766$ & $+/-21.768$ \\
\hline
\end{tabular}

\section{CONCLUSION}

This study was conducted to determine the activity of bioactive compounds contained in rosella against hPD-1/PD-L1 using in silico approach. We found 3 best compounds with the best binding energy and showed have an interaction with some catalitic residue. The best compounds were quercetin 3-rutinoside $(-7.6 \mathrm{kcal} / \mathrm{mol})$, delphinidin 3-sambubioside $(-7.1 \mathrm{kcal} / \mathrm{mol})$, and hibiscetin 3-glucoside $(-7.1 \mathrm{kcal} / \mathrm{mol})$. Molecular dynamics were carried out during $100 \mathrm{~ns}$ simulations, and from evaluation of the stability assessed by the RMSD and RMSF values showed that the three compounds have identical values and have good stability complex. The binding free energy was assessed by the MM-PBSA method showing that from the three compounds, delphinidin-3-sambubioside showed the best binding free energy than other compounds with total binding free energy $-33.161 \mathrm{KJ} / \mathrm{mol}$, while the hibiscetin-3-glucoside and quercetin-3-rutinoside showed total binding energy $-12.721 \mathrm{KJ} / \mathrm{mol}$ and -14.317 , respectively.

\section{ACKNOWLEDGEMENT}

We are grateful for the support of the Pharmacy Department of Universitas Padjadjaran and the Head of STIKES Mandala Waluya so the research can be carried out.

\section{REFERENCES}

1. F. Bray, J. Ferlay, I. Soerjomataram, R.L. Siegel, L.A. Torre, and A. Jemal, Cancer Journal for Clinicians. 68(6), 394(2018), DOI:10.3322/caac.21492

2. K.Y. Helmy, S.A. Patel, G.R. Nahas, and P. Rameshwar, Therapeutic Delivery, 4(10), 1307(2013), DOI: $10.4155 /$ tde. 13.88

3. C. Granier, S. Karaki, H. Roussel, C. Badoual, T. Tran, M. Anson, E. Fabre, S. Oudard, and E. Tartour, La Revue de Médecine Interne. 37(10), 694(2016), DOI:10.1016/j.revmed.2016.05.023

4. S. Joshi and D.L. Durden, Journal of Oncology, 9(1), 1(2019), DOI:10.1155/2019/5245034

5. Y. Pico de Coaña, A. Choudhury, and R. Kiessling, Trends in Molecular Medicine, 21(8), 482(2015), DOI: 10.1016/j.molmed.2015.05.005

6. V. Brower, Journal of the National Cancer Institute, 107(3), (2015), DOI:10.1093/jnci/djv069

7. J.B.A.G. Haanen and C. Robert, Progress in Tumor Research, 42(1), 55(2015), DOI: $10.1159 / 000437178$

8. S. Sivori, M. Della Chiesa, S. Carlomagno, Q. Linda, M. Enrico, V. Paola, T. Nicola, M.F. Romana, M.M. Cristina, P. Daniela, and M. Lorenzo, Frontiers in Immunology. 11, 2156(2020), DOI: $10.3389 /$ fimmu.2020.02156 
RASĀYAN J. Chem.

Vol. 14 | No. 2 |1394-1401| April - June | 2021

9. H. Yao, H. Wang, C. Li, J-Y. Fang, and J. Xu, Frontiers in Immunology, 9, 1774(2018), DOI: 10.3389/fimmu.2018.01774

10. J. Yu, X. Wang, F. Teng, and L. Kong, OncoTargets and Therapy, 9(1), 5023(2016), DOI: $10.2147 /$ OTT.S105862

11. Y. Wu, W. Chen, Z.P. Xu, and W. Gu, Frontiers in Immunology, 10, 2022(2019), DOI: $10.3389 /$ fimmu.2019.02022

12. S. Pesce, M. Greppi, F. Grossi, G.D. Zotto, L. Moretta, S. Sivori, C. Genova, and E. Marcenaro, Frontiers in Immunology, 10, 1242(2019), DOI:10.3389/fimmu.2019.01242

13. N. Patsoukis, Q. Wang, L. Strauss, and V.A. Boussiotis, Science Advances, 6(38), (2020), DOI: $10.1126 /$ sciadv.abd2712

14. A. Ganesan, M. Ahmed, I. Okoye, E. Arutyunova, D. Babu, W. L. Turnbull, J. K. Kundu, J. Shields, K.C. Agopsowicz, L. Xu, Y. Tabana, N. Srivastava, G. Zhang, T.C. Moon, A. Belovodskiy, M. Hena, A.S. Kandadai, S.N. Hosseini, M. Hitt, J. Walker, M. Smylie, F.G. West, A.G. Siraki, M.J. Lemieux, S. Elahi, J.A. Nieman, D.L. Tyrrell, M. Houghton and K. Barakat, Scientific Reports, 9(1), 12392(2019), DOI:10.1038/s41598-019-48826-6

15. I. Da-Costa-Rocha, B. Bonnlaender, H. Sievers, I. Pischel, and M. Heinrich, Food Chemistry, 165, 424(2014), DOI:10.1016/j.foodchem.2014.05.002

16. C. Mazewski, M.S. Kim, and E. de Mejia, Scientific Reports, 9(1), 11560(2019), DOI: 10.1038/s41598-019-47903-0

17. F.M. Afendi, T. Okada, M. Yamazaki, A. Hirai-Morita, Y. Nakamura, K. Nakamura, S. Ikeda, H. Takahashi, M. Altaf-Ul-Amin, L.K. Darusman, K. Saito, and S. Kanaya, Plant and Cell Physiology. 53(2), (2012), DOI:10.1093/pcp/pcr165

18. K. Nakamura, N. Shimura, Y. Otabe, A. Hirai-Morita, Y. Nakamura, N. Ono, M. Altaf Ul-Amin, and S. Kanaya, Plant and Cell Physiology. 54(2), e4(2013), DOI:10.1093/pcp/pcs186

19. S. Kim, P.A. Thiessen, E.E. Bolton, J. Chen, G. Fu, A. Gindulyte, L. Han, J. He, S. He, B.A. Shoemaker, J. Wang, B. Yu, J. Zhang, and S.H. Bryant, 44(1), 1202(2016), DOI:10.1093/nar/gkv951

20. K.M. Zak, R. Kitel, S. Przetocka, P. Golik, K. Guzik, B. Musielak, A. Domling, G. Dubin, and T.A. Holak, Structure, 23(12), 2341(2015), DOI:10.1016/j.str.2015.09.010

21. S.S. Murthy and B.T. Narsaiah, Rasayan Journal of Chemistry, 12(4), 2030(2019), DOI: $10.31788 /$ RJC.2019.1245475

22. C. Isaac, R. Narayanaswamy, and K. Vallivitan, Rasayan Journal of Chemistry, 14(1), 659(2021), DOI:10.31788/ RJC.2021.1416107

23. D. S. F. Ramadhan, T. M. Fakih, and Arfan, Borneo Journal of Pharmacy, 3(4), 235(2020). DOI:10.33084/bjop.v3i4.1634

24. Y. Sako, N. Yamaotsu, and S. Hirono, Journal of Computational Chemistry \& Molecular Modeling, 3(1), 212(2018), DOI: 10.25177/JCCMM.3.1.1

25. M.J. Abraham, T. Murtola, R. Schulz, S. Pálla, J.C. Smith, B. Hess, and E. Lindahl, SoftwareX. 1(2), 19(2015), DOI:10.1016/j.softx.2015.06.001

26. A.W. Sousa da Silva and W.F. Vranken, BMC Research Notes, 5(1), 367(2012), DOI:10.1186/17560500-5-367

27. U. Essmann, L. Perera, M. Berkowitz, T. Darden, H. Lee, and L. Pedersen, The Journal of Chemical Physics, 103, 8577(1995), DOI:10.1063/1.470117

28. P. Mark and L. Nilsson, The Journal of Physics Chemistry A, 105(43), 9954(2001), DOI: $10.1021 / \mathrm{jp} 003020 \mathrm{w}$

29. A.A. Parikesit and U.S.F. Tambunan, Rasayan Journal of Chemistry, 11(3), 1133(2018), DOI: $10.31788 /$ RJC.2018.1133038

30. S. Genheden and U. Ryde, Expert Opinion on Drug Discovery, 10(5), 449(2015), DOI: $10.1517 / 17460441.2015 .1032936$

31. D.A.E. Pitaloka, D.S.F. Ramadhan, Arfan, L. Chaidir, and T.M. Fakih, Scientia Pharmaceutica. 89(2), 20(2021), DOI:10.3390/scipharm 89020020

[RJC-6273/2020] 